\title{
Reservoir operation for hydropower optimization: A chance-constrained approach
}

\author{
K R SREENIVASAN and S VEDULA \\ Department of Civil Engineering, Indian Institute of Science, \\ Bangalore 560012, India \\ e-mail: [krsree,svedula]@civil.iisc.ernet.in \\ MS received 23 August 1995
}

\begin{abstract}
This paper presents a chance-constrained linear programming formulation for reservoir operation of a multipurpose reservoir. The release policy is defined by a chance constraint that the probability of irrigation release in any period equalling or exceeding the irrigation demand is at least equal to a specified value $P$ (called reliability level). The model determines the maximum annual hydropower produced while meeting the irrigation demand at a specified reliability level. The model considers variation in reservoir water level elevation and also the operating range within which the turbine operates. A linear approximation for nonlinear power production function is assumed and the solution obtained within a specified tolerance limit. The inflow into the reservoir is considered random. The chance constraint is converted into its deterministic equivalent using a linear decision rule and inflow probability distribution. The model application is demonstrated through a case study.
\end{abstract}

Keywords. Reservoir operation; hydropower; optimization; chance constraint; rule curve.

\section{Introduction}

Operation of a multipurpose reservoir for irrigation and hydropower requires a strategy, as water is to be used for two conflicting demands. The available storage has to be allocated for multiple purposes considering stochasticity of inflow. Hydropower optimization for a multipurpose reservoir for fixed irrigation demand and deterministic supply was studied by Sreenivasan \& Vedula (1994). Reservoir operation for irrigation at specified level of reliability (with inflow treated as a random variable) was studied by Vedula \& Sreenivasan (1992). The present study combines the features of these two studies in optimizing the hydropower production from a multipurpose reservoir with random inflows and with a specified reliability of meeting irrigation demand. Chance-constrained linear programming 
(CCLP) is used in the model formulation. The model determines (i) the maximum annual hydropower that can be produced while meeting the irrigation demand at a specified level of reliability, and (ii) the end-of-period storages (rule curve) to be maintained in the reservoir. The release policy is expressed through a chance constraint. The nonlinear hydropower production function, being a product of the power release and the head acting over the turbine, is linearized using the approximation given in Loucks et al (1981, pp 248-9). The model considers variation in the hydrodynamic head on the turbine consequent to a variation in reservoir water level elevation and also the range within which the turbine operates.

A reservoir system operated for irrigation and hydropower typically consists of a reservoir with left and right bank canals leading to the irrigated area, and a powerhouse at the bed of the river. The irrigation canals may also have powerhouses on them. Power is produced in them through a diversion of the irrigation releases into the canals. The river bed turbine produces power only through the release made downstream of the reservoir. In the present study, a lumped irrigation demand is considered at the reservoir as a release requirement (into the canals) for irrigation.

\section{Objective}

The objective of the study is to formulate a mathematical programming model to determine (i) the maximum annual hydropower produced from a multipurpose reservoir, while meeting the irrigation demands for various specified levels of reliability, and (ii) rule curve storages for the optimal operation of the reservoir.

\section{The model}

The model is formulated for a single reservoir serving multiple purposes (irrigation and hydropower). Inflow into the reservoir is considered random. The head on the turbine varies from time to time consequent to a change in the reservoir water level. Also, hydropower can be produced only when the reservoir water level lies in the operating range specified for the reservoir. No power can be produced outside of this range. Chance-constrained linear programming is used in the formulation.

\subsection{Release policy}

The reservoir release policy is defined by the chance constraint equation (1) below, which states that the probability ( $P r)$ of irrigation release in time period $t$ equalling or exceeding the irrigation demand, is not less than a specified value $P . P$ is referred to hereafter as the reliability level.

$$
\operatorname{Pr}\left[I R A_{t} \geq I D_{t}\right] \geq P
$$

where $I R A_{t}$ is the irrigation release during period $t, I D_{t}$ is the irrigation demand for period $t$, and $P$ is the specified reliability level. 


\subsection{Reservoir water balance}

The reservoir storage continuity relationship is expressed as

$$
S_{t}+I_{t}-I R A_{t}-B P_{t}-E V_{t}=S_{t+1},
$$

where $S_{t}$ is the storage at the beginning of period $t, I_{t}$ is the random inflow into the reservoir, $I R A_{t}$ is the irrigation release, $B P_{t}$ is the downstream release (assumed deterministic) for bed power production, and $E V_{t}$ is the evaporation loss during period $t . E V_{t}$ is approximated (in the range of active storage) by a linear relationship of the form

$$
E V_{t}=\alpha_{t}+\beta_{t}\left(S_{t}+S_{t+1}\right)
$$

where $\alpha_{t}$ and $\beta_{t}$ are coefficients depending on the period $t$. Substituting for the evaporation term from (3) into (2), and rearranging we get

$$
I R A_{t}=\left(1-\beta_{t}\right) S_{t}-\left(1+\beta_{t}\right) S_{t+1}+I_{t}-B P_{t}-\alpha_{t} .
$$

Substituting (4) into the chance constraint equation (1), one gets

$$
\operatorname{Pr}\left[\left(1+\beta_{t}\right) S_{t+1}-\left(1-\beta_{t}\right) S_{t}+B P_{t}+\alpha_{t}+I D_{t} \leq I_{t}\right] \geq P .
$$

This is the final form of the chance constraint. The deterministic equivalent is written using a linear decision rule (LDR) as follows.

\subsection{Linear decision rule}

The following linear decision rule is considered,

$$
I R A_{t}=S_{t}+I_{t}-B P_{t}-E V_{t}-b_{t}
$$

where $b_{t}$ is a non-random, non-negative operating policy parameter. Equation 6 indicates a release equal to the total available quantity, $S_{t}+I_{t}-B P_{t}-E V_{t}$, less some fixed amount $b_{t}$.

Substituting (6) into the reservoir continuity equation (2), the linear storage rule is obtained,

$$
S_{t+1}=b_{t} .
$$

Employing this rule in (6) it can be seen that variance of inflow is directly transferred to the irrigation release, as $E V_{t}$ and $B P_{t}$ are functions of storage, both of which are now deterministic.

\subsection{Deterministic equivalent}

Substituting (7) in the chance constraint equation (5), the deterministic equivalent is written as

$$
\left(1+\beta_{t}\right) b_{t}-\left(1-\beta_{t}\right) b_{t-1}+B P_{t}+\alpha_{t}+I D_{t} \leq I_{t}^{(1-P)},
$$

where $I_{t}^{(1-P)}$ is the reservoir inflow during period $t$ with probability $(1-P)$, or exceedance probability $P$. 


\subsection{Other constraints}

3.5a Storage capacity constraints: The storage in any time period $t$ shall not be less than dead storage capacity $\left(K_{d}\right)$ and shall not exceed the total capacity of the reservoir $(K)$.

$$
\begin{aligned}
& b_{t-1} \geq K_{d}, \\
& b_{t-1} \leq K,
\end{aligned}
$$

with

$$
b_{0}=b_{12}
$$

3.5b Power plant capacity: The energy produced by the bed turbine in any time period $t, E B_{t}$, shall not exceed that corresponding to the installed capacity of the turbine, $B P C$, thus

$$
E B_{t} \leq B P C
$$

3.5c Head-storage relationship: For computing the head over the turbine, the reservoir elevation $H_{t}$, in any period $t$ above the river bed is taken to be the average of the elevations at the beginning and end of the period. The following linear relationship is assumed within the range of storages defined by (9) and (10).

$$
H_{t}=\gamma\left[\left(b_{t-1}+b_{t}\right) / 2\right]+\delta,
$$

where $\gamma$ is the slope of the linear portion of the elevation-storage curve, and $\delta$ is the intercept.

3.5d Linear approximation for power production function: A linear approximation of the nonlinear power production term, $E B_{t}=c\left\{B P_{t}\left(H_{t}-B T A I L\right)\right\}$ is expressed, following Sreenivasan \& Vedula (1994), as

$$
E B_{t}=c\left[B P_{t}\left(H_{t}^{0}-B T A I L\right)+B P_{t}^{0}\left(H_{t}-B T A I L\right)-B P_{t}^{0}\left(H_{t}^{0}-B T A I L\right)\right]
$$

where $B P_{t}^{0}$ is the approximate value for the bed power release $B P_{t}$, in period $t$, and $H_{t}^{0}$ is the approximate value for the reservoir elevation $H_{t}$ in period $t, B T A I L$ is the tail race elevation of the bed turbine above river bed, and $c$ is a constant to convert the product of the rate of flow and head over the turbine to the energy produced from the turbine in period $t$. This constraint will be active only when the reservoir elevation is within the operating range ( $H_{\min } \leq H_{t} \leq H_{\max }$ ) for bed turbine operation, $H_{\min }$ and $H_{\max }$ being specified. $E B_{t}$ is set to zero outside this range.

\subsection{Objective function}

The objective is to maximize the annual hydropower production by the bed turbine,

$$
\text { Maximize } \sum_{t} E B_{t} \text {. }
$$

The objective function (14) along with constraints, (8) through (13), constitutes the chance-constrained linear programming formulation. 


\section{Methodology}

The CCLP model is run for a specified value of $P$ (reliability of meeting irrigation demand). Initially, the solution is obtained by assuming some reasonable values $H_{t}^{0}$ and $B P_{t}^{0}$. If the values of $H_{t}$ and $B P_{t}$ in the solution are different from these, then a second run is made replacing $H_{t}^{0}$ and $B P_{t}^{0}$ by $H_{t}$ and $B P_{t}$ respectively. Thus the CCLP model is run successively each time replacing the values of $B P_{t}^{0}$ by $B P_{t}$ and $H_{t}^{0}$ by $H_{t}$ till convergence is obtained as explained in the paper by Sreenivasan \& Vedula (1994). The optimal solution is assumed to have converged when $H_{t} \simeq H_{t}^{0}$ and $B P_{t} \simeq B P_{t}^{0}$, within a specified tolerance limit (set as $10^{-3}$ in the present study). In a similar manner, the model is run for different specified levels of reliability, each time with a reliability higher than in the earlier run, till the solution becomes infeasible. The highest possible reliability level of meeting the irrigation demands associated with the given inflow series and the reservoir capacity is thus determined.

\section{Application}

The model is applied to a reservoir system in South India. The total capacity of the reservoir is $2024 \mathrm{Mm}^{3}$ with a dead storage capacity of $240 \mathrm{Mm}^{3}$. For the model application in the present study, it is conceptualized that the reservoir releases water to a composite command comprising the left and right bank command areas through a single irrigation canal. This is done because of the model limitation in its inability to deal with two different random releases (into left and right bank canals) both of which have the same source of supply (reservoir). The model is applied using the month as the time period.

The installed capacity of the bed turbine is $24000 \mathrm{~kW}$. The value of $c=0.002268$ in (13), where $E B_{t}$ is in $10^{6}$ kilowatt hours, $B P_{t}$ and $H_{t}$ are expressed in $10^{6}$ cubic metres and metres respectively. The value of $B P C$ (the energy corresponding to the installed capacity of the riverbed turbine) works out to 10.87 million kilowatt hours per month (for a standard month of 730.5 hours with an assumed load factor of 0.62 ).

The total hydropower produced consists of the power produced by the canal powerhouses and the riverbed powerhouse. The canal powerhouse production depends on the irrigation release, which is decided by the reliability criterion. The power produced from the canal powerhouse is therefore incidental to this release. Because of this, only the riverbed-turbine power production is optimized in the present study. Hydropower production, henceforth referred to in the paper means only bed turbine power production.

\section{$5.1 \quad$ Data}

Analysis of available data revealed that $\gamma=0.0135$ and $\delta=30.6$ in (12) from elevationstorage curve of the reservoir (elevation in metres and storage in $10^{6}$ cubic metres). Monthly inflow data of 52 years (from 1930-31 to 1981-82) were used to prepare the appropriate inflow sequence to be used in a given run. Inflows in each month are ranked and the appropriate values at a specified probability level determined using the Weibull formula. Table 1, for example, gives monthly inflows with $P=0.65$, along with the irrigation demands. 
Table 1. Inflows at $P=0.65$ and irrigation demands.

\begin{tabular}{lcc}
\hline Month & $\begin{array}{c}\text { Inflow } \\
(P=0.65) \\
\left(\mathrm{Mm}^{3}\right)\end{array}$ & $\begin{array}{c}\text { Irrigation } \\
\text { demand } \\
\left(\mathrm{Mm}^{3}\right)\end{array}$ \\
\hline Jun & 163.40 & 119.90 \\
Jul & 813.20 & 136.80 \\
Aug & 702.97 & 200.60 \\
Sep & 261.73 & 195.80 \\
Oct & 202.81 & 203.20 \\
Nov & 89.31 & 189.70 \\
Dec & 50.52 & 109.40 \\
Jan & 26.93 & 137.30 \\
Feb & 17.10 & 180.10 \\
Mar & 10.64 & 197.39 \\
Apr & 11.70 & 197.90 \\
May & 11.06 & 178.60 \\
\hline
\end{tabular}

In (3) values of $\alpha=7.388$ and $\beta=0.003$ were used in place of $\alpha_{t}$ and $\beta_{t}$ respectively, for all $t$, for the reservoir under study as given by Vedula et al (1986). The minimum and maximum reservoir elevations for the bed turbine operation are specified as $H_{\min }=$ $36.88 \mathrm{~m}$ and $H_{\max }=56.693 \mathrm{~m}$ above the riverbed.

\section{Results and discassion}

Model runs were made for different reliability levels in increasing order in steps of 0.05 . The maximum possible reliability for meeting the irrigation demand is found to be 0.65 and the associated maximum annual hydroenergy produced by the bed turbine is $5.68 \mathrm{M} \mathrm{kw} \mathrm{h}$. Table 2 shows the maximized annual hydropower produced by the bed turbine for various reliability levels of meeting the irrigation requirement. Figure 1 presents a plot of reliability vs hydropower produced. From the curve one can find the maximum annual energy that can be produced by the bed turbine for a specified reliability level of meeting the irrigation demands; or alternatively, one may find the maximum reliability of irrigation associated with a given level of hydropower production.

Table 3 shows model results for a reliability level $P$ of 0.65 . The table gives the downstream release for the bed turbine, reservoir water elevation, hydropower produced by the

Table 2. Reliability and annual bed turbine power production.

\begin{tabular}{lrrrr}
\hline Reliability* & 0.50 & 0.55 & 0.60 & 0.65 \\
Energy produced (M kwh) & 56.17 & 40.10 & 17.40 & 5.68 \\
\hline
\end{tabular}

${ }^{*}$ Of meeting irrigation demand 


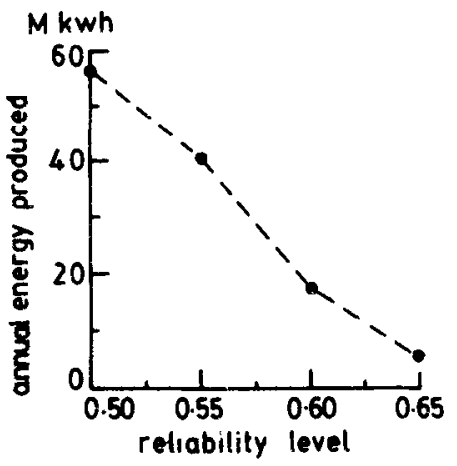

Figure 1. Annual energy produced vs reliability.

bed turbine and end-of-period storage in each period. The end-of-period storages define the rule curve for reservoir operation. Figure 2 presents the rule curve for optimal operation of the reservoir for $P=0.65$.

\section{Conclusions}

A chance-constrained linear programming model is formulated for a multipurpose reservoir to determine the maximum annual hydropower production by the bed turbine, while meeting the irrigation requirements at a specified level of reliability for given reservoir capacity. The model considers (i) a linear approximation for the nonlinear power production function. (ii) variations in the head over the turbine in each period, and (iii) operating range of reservoir water levels for bed turbine power production.

The model can be used to determine (i) the maximum annual hydropower that can be produced at different levels of reliability (of meeting the irrigation demands), and (ii)

Table 3. Model results.

\begin{tabular}{crccc}
\hline Period & $\begin{array}{c}\text { Power } \\
\text { release } \\
\left(\mathrm{Mm}^{3}\right)\end{array}$ & $\begin{array}{c}\text { Reservoir } \\
\text { elevation } \\
(\mathrm{m})\end{array}$ & $\begin{array}{c}\text { Energy } \\
\text { produced } \\
(\mathrm{M} \mathrm{kw})\end{array}$ & $\begin{array}{c}\text { End-of-period } \\
\text { storage } \\
\left(\mathrm{Mm}^{3}\right)\end{array}$ \\
\hline 1 & 0.000 & 33.290 & 0.000 & 266.228 \\
2 & 0.000 & 37.731 & 0.000 & 923.306 \\
3 & 0.000 & 45.120 & 0.000 & 1402.948 \\
4 & 60.454 & 48.117 & 5.678 & 1384.308 \\
5 & 0.000 & 47.837 & 0.000 & 1359.935 \\
6 & 0.000 & 46.873 & 0.000 & 1236.000 \\
7 & 0.000 & 45.536 & 0.000 & 1154.201 \\
8 & 0.000 & 44.142 & 0.000 & 1021.551 \\
9 & 0.000 & 42.082 & 0.000 & 837.220 \\
10 & 0.000 & 39.539 & 0.000 & 630.409 \\
11 & 0.000 & 36.862 & 0.000 & 425.288 \\
12 & 0.000 & 34.324 & 0.000 & 240.000 \\
\hline
\end{tabular}




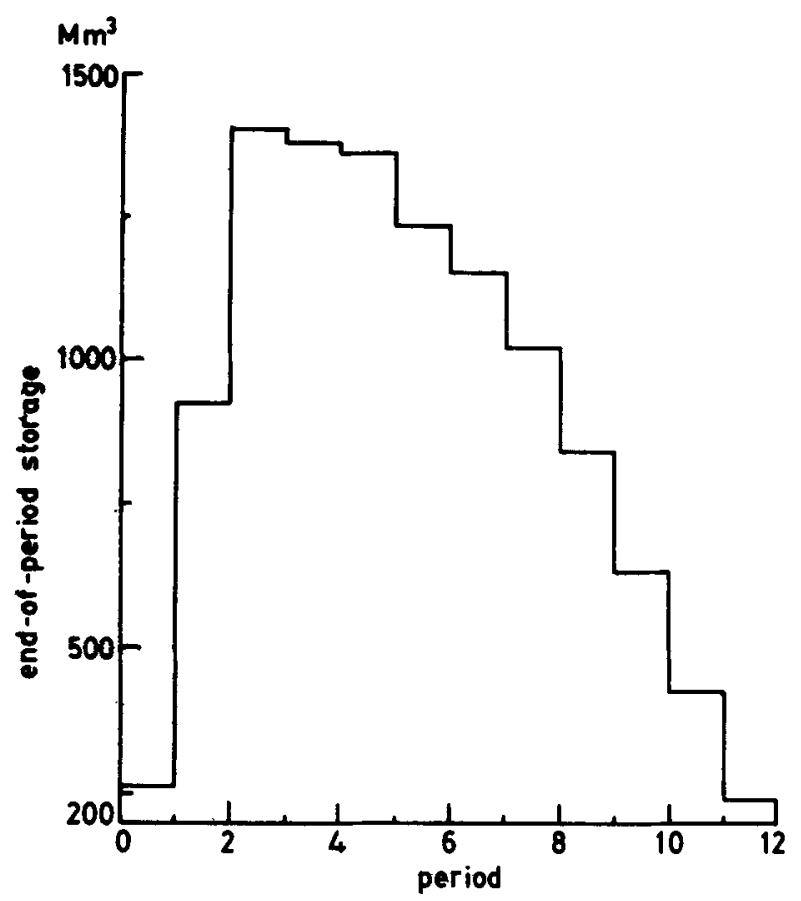

Figure 2. End-of-period storage for $P=0.65$.

the optimal end-of-period storages (rule curve storages) for reservoir operation. Also, the maximum reliability of irrigation associated with a given level of hydropower production can be determined.

\section{References}

Loucks D P, Stedinger J R, Haith D A 1981 Water resources systems planning and analysis (Englewood Cliffs, NJ: Prentice Hall)

Sreenivasan K R, Vedula S 1994 Hydropower optimization in a multipurpose reservoir. Proc. National Seminar on Water and Environment, Thiruvananthapuram, pp. 2.49-2.54

Vedula S, Mohan S, Shreshtha V S 1986 Improved operating policies for multipurpose use: A case study of Bhadra Reservoir. Sadhana 9: 157-176

Vedula S, Sreenivasan K R 1992 Reliability based reservoir irrigation options and rule curves.

Proc. VIII APD-IAHR Congress, Pune, vol. 1, pp. A-263-A275 